\title{
Direitos fundamentais e Bioética
}

\author{
Luiza Matte ${ }^{*}$
}

\section{INTRODUÇÃO}

O crescente interesse do staff jurídico, mormente da comunidade acadêmica, nas questões bioéticas, por si só justificaria o presente artigo.

De outra banda, a íntima conexão entre uma "ética da vida" e o maior princípio do ordenamento constitucional brasileiro, qual seja, o Princípio da Dignidade da Pessoa Humana, centra o foco deste trabalho nas relações entre os direitos fundamentais, derivados de tal dignidade, e a Bioética.

Assim, necessário se faz que iniciemos por conceituar e definir os campos próprios aos direitos fundamentais e à Bioética. Antes, porém, de debruçar-nos sobre as conexões entre estes campos, é preciso que se dediquem algumas palavras ao papel determinante da ética nos dias atuais e sobre sua vinculação às demais ciências.

Uma vez estabelecidos pontos comuns entre direitos fundamentais e Bioética, analisa-se o caso específico de nosso país, passando-se a estudar, de forma breve, concisa e exemplificativa, o elenco de direitos fundamentais constantes da Constituição brasileira de 1988. Com isto, busca-se identificar os problemas e as conseqüências trazidos pelo avanço da técnica biomédica em relação a estes direitos, e procura-se definir o papel do sistema de direitos fundamentais da Constituição frente às questões bioéticas.

Chega-se, deste modo, à conclusão de que, para além da importante função que desempenha a própria Constituição Federal, seus princípios e sua

\footnotetext{
"Bacharel em Direito pela UFRGS; mestre pela PUCRS; professora de Direito na PUCRS e na Faculdade de Direito São Judas Tadeu, em Porto Alegre.
} 
interpretação pelos tribunais neste assunto, é urgente a instauração do debate sobre o desenvolvimento de normas infraconstitucionais e instituições aptas a permitir a concretização, em termos jurídicos, das soluções para os problemas em tela.

\section{DEFINIÇÕES E ALCANCE DOS CAMPOS DA BIOÉTICA E DOS DIREITOS FUNDAMENTAIS}

\subsection{Dos Direitos Fundamentais}

Ao iniciarmos o tópico acerca dos direitos fundamentais, o primeiro ponto a que devemos atentar é a questão da terminologia. Há, em verdade, grande celeuma em relação a este ponto, apontando a maioria dos autores outras expressões, que, ainda que guardem diferenças, são corriqueiramente usadas como sinônimos de "direitos fundamentais". Entre essas expressões podemos citar: direitos humanos, direitos individuais, liberdades públicas, direitos públicos subjetivos, direitos naturais, etc.

No presente trabalho, opta-se por não aprofundar tal questão, vez que suficientemente esclarecida pela doutrina e de caráter acessório ao tema principal que aqui pretendemos abordar. Esclarece-se, então, que usaremos a expressão "direitos fundamentais" por ser esta a empregada na Constituição brasileira e por considerar-se sua ampla aceitação no meio jurídico.

Como se disse, a Constituição brasileira de 1988 traz, como sempre trouxeram nossas constituições, uma declaração de direitos e garantias considerados fundamentais. Segundo Luiz Araújo e Vidal Nunes Júnior, “[...] o termo fundamental destaca a imprescindibilidade desses direitos à condição humana."' Estes direitos são considerados fundamentais porque, sem eles, a pessoa não tem as condições mínimas de viver em sociedade.

Como ensina José Afonso da Silva, ${ }^{2}$ o pensamento cristão e a concepção de direitos naturais são as principais fontes de inspiração das declarações de direitos e muitos entendem que os direitos fundamentais são direitos que derivam diretamente da natureza humana.

Na verdade, podemos compreendêlos como "irradiações" da dignidade da pessoa humana, como vários autores fazem. ${ }^{3}$ Assim, eles não são "concedidos" pelo Estado, o Estado

1 ARAÚJO, Luiz Alberto David e NUNES JÚNIOR, Vidal Serrano. Curso de Direito Constitucional. 8. ed. São Paulo: Saraiva, 2004, p. 92.

2 SILVA, José Afonso da. Curso de Direito Constitucional positivo. 22. ed. São Paulo, Malheiros, 2003, p. 172.

3 Neste sentido: "Os direitos fundamentais podem ser conceituados como a categoria jurídica instituída com a finalidade de proteger a dignidade humana em todas as dimensões." (ARAÚJO; NUNES JÚNIOR, op. cit.). 
simplesmente tem de reconhecer a sua existência, se objetivar ser um Estado democrático e que efetivamente sirva a seu fim: a própria pessoa humana.

O fato de virem enunciados na Constituição em primeiro lugar, antes mesmo da organização do Estado, evidencia que a pessoa humana é o fim do Estado, é sua causa material, ontologicamente superior ao ente "Estado".

Como os direitos fundamentais historicamente derivam do liberalismo individualista, outra dificuldade a superar é a sua identificação com os direitos de defesa do indivíduo em relação ao Estado, os direitos individuais por excelência, e os primeiros a serem incorporados às Constituições. Entretanto, sabe-se que tais direitos individuais de cunho negativo provaram-se insuficientes para garantir o pleno desenvolvimento da personalidade de cada um e do bem comum em sociedade. Assim, foram sendo paulatinamente incluídos sob a efígie de fundamentais, outros direitos de feição econômica, social, cultural, etc., enriquecendo a enunciação clássica dos primeiros tempos do constitucionalismo. Tal caminho é adotado também na Constituição brasileira, como se observa da análise dos capítulos listados sob o título de direitos e garantias fundamentais (direitos e deveres individuais e coletivos, direitos sociais e de nacionalidade, e direitos políticos).

É, aliás, da ampliação da gama de direitos fundamentais que derivam as várias classificações que encontramos na doutrina.
Outra conseqüência desta ampliação dos direitos fundamentais é a abertura material do catálogo constitucional destes direitos. Como se vê da sua própria evolução, os direitos fundamentais são também direitos históricos, que surgem aos poucos das lutas por liberdade e pelo aprimoramento das condições de vida, sendo produto da civilização e do progresso humanos. A idéia de liberdade, por exemplo, foi se tornando cada vez mais específica, diferenciando-se a idéia abstrata, de liberdades concretas (de expressão, de associação, etc.). O mesmo ocorreu com relação aos titulares dos direitos, que, de genéricos, passaram a ser cada vez mais específicos, diferenciando-se mulheres de homens, crianças de idosos e assim por diante. Nota-se, ainda, um aumento na quantidade de bens considerados merecedores de tutela. $\mathrm{E}$, por fim, ocorreu a passagem dos chamados direitos de liberdade para os direitos políticos e sociais, que requerem intervenção direta do Estado.

Os direitos fundamentais, portanto, estão em permanente renovação, daí a abertura preconizada na Constituição ser algo lógico, pois, com relação ao conteúdo ou à quantidade dos direitos elencados, as declarações constitucionais de direitos não podem ter pretensão de ser definitivas. Neste sentido, conforme o $\S 2^{\circ}$ do art. $5^{\circ}$ da Constituição, o catálogo de direitos fundamentais não se esgota na enumeração feita por este artigo, pois admite-se a possibilidade de existência 
de outros direitos fundamentais decorrentes dos próprios princípios enunciados na Constituição ou de tratados internacionais adotados pelo Brasil.

Uma vez adjetivados os direitos fundamentais como históricos e evolutivos, uma das classificações mais difundidas modernamente é a que atenta justamente a estes fatores, organizando os direitos fundamentais em gerações ou dimensões, conforme tenham sido reconhecidos ao longo do tempo pelas constituições.

A doutrina, então, tem dividido os direitos fundamentais em três gerações e cogita-se, atualmente, de uma quarta geração. Vejamos uma por uma, conforme colocadas na obra de Ingo Wolfgang Sarlet. ${ }^{4}$

Os direitos de primeira dimensão, ou a primeira geração de direitos são aqueles que surgiram da filosofia liberal, inspirada no individualismo, são direitos de defesa do indivíduo perante o Estado, direitos que servem para criar uma esfera de autonomia ao indivíduo onde o Estado não possa intervir. Por este motivo, diz-se que estes direitos são de cunho negativo, pois exigem do Estado uma abstenção (não intervir) e não uma ação positiva. São direitos baseados também, como vimos, no jusnaturalismo e na filosofia cristã, ressaltando-se o direito à vida, à liberdade, à propriedade e à igualdade perante a lei. Os desdobramentos da liberdade e da igualdade (liberdade de expressão, de crença, de associação, igualdade entre sexos, raças, etc.) incluem-se nesta primeira geração, bem como os direitos de participação política e algumas garantias constitucionais a estes direitos, como o habeas corpus e o devido processo legal. São, em suma, os chamados direitos civis e políticos.

A segunda geração de direitos compreende aqueles direitos reivindicados a partir da constatação da ineficácia do sistema liberal clássico, das dificuldades advindas da industrialização e de idéias socialistas, que são os chamados direitos sócio-econômicos e culturais.

A nota distintiva destes direitos é a sua dimensão positiva, pois não mais se busca evitar a intervenção do Estado na esfera de liberdade individual. $O$ que se busca é uma ação positiva do Estado para que todos possam participar do bem-estar social. O Estado deve garantir prestações sociais como previdência social, saúde, educação, trabalho, etc. As liberdades sociais envolvem o direito de greve, a liberdade de sindicalização e os direitos dos trabalhadores, como férias, salário mínimo, limitação de jornada, etc. Não é mais uma questão de liberdade perante o Estado, mas, sim, de liberdade por intermédio do Estado.

Os direitos sociais buscam equilibrar o interesse do grupo e o

4 Cf. SARLET, Ingo Wolfgang. A eficácia dos direitos fundamentais. Porto Alegre: Livraria do Advogado, 1998. 
interesse particular do homem; são, portanto, direitos meta-individuais.

No Brasil, são direitos relativamente novos, que passaram a ser regulados principalmente a partir da Constituição de 1934. A Constituição de 1988 trouxe algumas conquistas legislativas, como, por exemplo, a licença paternidade, o direito ao lazer e outras.

Como se disse, os direitos sociais têm cunho positivo, ou seja, na maioria das vezes, requerem ações por parte dos poderes públicos e o sujeito passivo destes direitos é o Estado. Daí que, como ensina Ingo Sarlet, ${ }^{5}$ a efetividade destes direitos enfrenta uma série de problemas, pois depende da tomada de providências por parte do Estado.

Precisamos frisar que, ainda que sejam chamados de direitos sociais, os direitos da segunda geração ainda contemplam o indivíduo e não podem ser confundidos com os direitos difusos ou coletivos, que integram a terceira dimensão.

Então, os direitos da terceira dimensão ou geração são aqueles que se desprendem da figura individual como seu titular, visando a proteção de grupos humanos (família, nação, povo) e caracterizando-se, conseqüentemente, como direitos de titularidade difusa ou coletiva.

Os direitos da terceira geração são também chamados de direitos de solidariedade ou fraternidade, porque são transindividuais e por exigirem esforços e responsabilidade em escala até mundial para a sua efetivação. São exemplos destes direitos o direito à paz, à autodeterminação dos povos, ao meioambiente e à qualidade de vida, bem como o direitos à conservação e utilização do patrimônio histórico e cultural e o direito de comunicação.

Ainda quanto à terceira dimensão, muitos dos direitos que a compõem ainda não têm previsão constitucional, estando, por outro lado, em fase de consagração no âmbito do direito internacional, principalmente no que tange à qualidade de vida e ao meioambiente, que, como se disse, são questões mundiais.

E é neste ponto que surge uma zona de direitos que causa dúvida na doutrina, alguns sustentando que já se trataria de uma quarta geração de direitos, e outros colocando dentro da terceira geração aqueles direitos relativos às novas tecnologias biomédicas e de informação. Outros, ainda, como o jurista cearense Paulo Bonavides, ${ }^{6}$ dizem que a quarta geração de direitos diria respeito ao direito à democracia, que envolve direito de pluralismo e de informação. A quarta geração seria fruto da globalização dos direitos e valores fundamentais à pessoa humana.

5 SARLET, $A$ eficácia...

6 BONAVIDES, Curso de..., p. 525. 
$\mathrm{Na}$ realidade, todos os direitos fundamentais derivam da dignidade da pessoa humana e das tentativas que se fazem de respeitá-la sempre e cada vez mais; portanto, sejam três, quatro ou cinco dimensões ou gerações, isto é um pouco secundário. O importante é que vemos o direito evoluindo neste sentido da preservação da dignidade da pessoa humana, incorporando e especializando novos direitos, aceitos, na maior parte das vezes, de forma mundial.

\subsection{Da Bioética}

O termo Bioética surgiu no início da década de $1970,{ }^{7}$ construindo-se, a partir daí e até hoje, o seu conceito. Trata-se, portanto, de um termo novo e de um conceito novo da ciência contemporânea. A preocupação com as questões que ela sucita, porém, nada tem de nova, remetendo-nos, por exemplo, ao famoso médico grego Hipócrates, que viveu no século $\mathrm{V}$ a.C.

De acordo com Joaquim Clotet, que nos traz um conceito simples e abrangente, "a Bioética poderia ser definida brevemente como a abordagem dos problemas éticos ocasionada pelo avanço extraordinário das ciências biológicas, bioquímicas e médicas."
Já no que tange ao alcance da Bioética, adentramos em seara mais controversa, eis que a opinião dos autores costuma dividir-se neste tópico. A julgar por algumas posições e pelo próprio sentido da palavra "Bioética", derivado da soma das palavras gregas "bios" (vida) e "ethiké" (ética), seu objeto seria extremamente amplo. Parece-nos, contudo, que tal posicionamento não seja o mais adequado no sentido do desenvolvimento desta ciência.

Há unanimidade quanto a considerar-se a Bioética, metodologicamente, como um saber multi e interdisciplinar, denotando a importância do valor "vida" para todos os campos do conhecimento humano. Assim, muita vez se vêem incluídos em seu esteio questões relativas a todas as formas de vida, por exemplo, à vida animal e ao meio ambiente. Tal visão não é errônea. Crê-se, entretanto, que a Bioética poderia ser melhor desenvolvida, especialmente na sua ligação com o Direito, se os assuntos por ela tratados fossem de certa maneira restringidos. Esta restrição dar-se-ia, primeiramente, no sentido de relacionar a Bioética especialmente à forma de vida humana. Ainda assim,

7 A doutrina aponta o médico americano Van Rensselaer Potter como criador do termo, utilizado pela primeira vez em um artigo intitulado "Bioethics, the science of survival", publicado em 1970. (cf. DURAND, Guy. Introdução geral à Bioética: história, conceitos e instrumentos. Tradução Nicolás Nyimi Campanário.São Paulo: Editora do Centro Universitário São Camilo e Edições Loyola, 2003. p. 19).

8 CLOTET, Joaquim. Bioética: uma aproximação. Porto Alegre: Edipucrs, 2003, p. 27. 
restam nebulosos os limites entre vida humana e outras formas de vida a ela interligadas inevitavelmente. Por isso, achamos especialmente interessantes as idéias de Guy Durand neste ponto. Este autor canadense, ao tratar do objeto da Bioética, divide os temas por ela abraçados em um núcleo central, temas periféricos e questões subjacentes. ${ }^{9}$

O núcleo central da Bioética, para Durand, trata dos seguintes temas:

- aborto, diagnóstico pré-natal, aconselhamento genético, eutanásia fetal;

- inseminação artificial, fecundação artificial, bancos de esperma, bebês de proveta, "barriga de aluguel";

- manipulação genética, registro de genes, clonagem;

- critérios de esterilização, eugenismo;

- transexualismo;

- doação de órgãos humanos, transplantes entre espécies diferentes;

- HIV, AIDS;

- tratamentos no fim da vida, obstinação terapêutica, interrupção de tratamento, eutanásia, suicídio assistido;

- neurocirurgia, psicotrópicos, química do sistema nervoso;

- experimentação com o ser humano, com o embrião, com os tecidos humanos;

- pesquisa sobre o genoma;

- saúde pública, pesquisas epidemiológicas, etc.;

- alocação de recursos e políticas da saúde.
Os temas periféricos seriam:

- contracepção;

- controle demográfico;

- pesquisa e desenvolvimento de armas biológicas e químicas;

- guerra, tortura e pena de morte;

- patenteamento de seres vivos;

- pesquisa com animais;

- ecologia e meio ambiente.

Como questões subjacentes, surgem:

- concepção da saúde e da doença;

- sentido do corpo humano;

- sentido da reprodução;

- sentido da medicina;

- relação entre ética e direito;

- relação entre ética e tecnociências, etc.

A classificação de Durand leva em consideração, obviamente, os problemas com que nos deparamos no momento atual, sem pretensões de esgotá-los. $\mathrm{E}$, como se disse, o autor reconhece, como aqui também se faz, a dificuldade em precisar os limites entre estas áreas.

De qualquer modo, parece-nos adequada a fixação de um núcleo central de temas objeto da Bioética, para que o seu estudo não se perca em um espaço por demais amplo e para que, no afã de integrar as ciências e os diversos ramos destas ciências, terminemos por descentralizar a discussão a ponto de não conseguirmos aprofundá-la. 


\section{A ÉTICA E AS CIÊNCIAS}

Antes de passarmos a abordar a ligação da Bioética e dos direitos fundamentais, quando começaremos a pensar no papel do Direito em relação à biotecnologia, parece-nos interessante dedicar algumas palavras sobre a aplicação da Ética à técnica e às ciências em geral.

$\mathrm{Na}$ fase histórica em que nos encontramos atualmente, parece haver um renascimento da Ética, fato que não escapa à maioria dos filósofos contemporâneos, vide, no Direito, por exemplo, o crescente interesse na ética aristotélico-tomista e nos conceitos de phronesis ou prudência, ${ }^{10}$ muito úteis, aliás, ao deslinde das questões Bioéticas.

A própria existência da Bioética evidencia, após décadas de rigor e "neutralidade" científicos, um apelo às considerações filosóficas e axiológicas. María Casado ressalta este aspecto, dizendo que "resulta claramente constatable una tendencia a la revalorización de todo aquello que tiene que ver com la Ética"."1
Hans Jonas é um dos autores que procura responder por que a técnica moderna é objeto da filosofia, questão que inaugura o primeiro capítulo de seu livro Técnica, Medicina e Ética. Desta obra, retiramos as seguintes passagens, por considerá-las bastante esclarecedoras:

Dado que hoy en día la técnica alcanza casi todo lo que concierne a los hombres - vida y muerte, pensamiento y sentimiento, acción y padecimiento, entorno y cosas, deseos y destino, presente y futuro - en resumen, dado que se há convertido en un problema tanto central como apremiante de toda la existencia humana sobre la tierra, ya es un asunto de la filosofía, y tiene que haber algo así como una filosofía de la tecnología. ${ }^{12}$

Dicho de forma muy general, que la ética tiene algo que decir en las cuestiones relacionadas com la técnica o que la técnica está sometida a consideraciones éticas se desprende del sencillo hecho de que la técnica es un ejercicio de poder humano, es decir, una forma de actuación, y toda actuación humana está expuesta a su examen moral. ${ }^{13}$

10 Destaca-se o trabalho do filósofo do Direito e professor Luís Fernando Barzotto, em, por exemplo, Prudência e jurisprudência - uma reflexão epistemológica sobre a jurisprudentia romana a partir de Aristóteles (BARZOTTO, Luís Fernando. Prudência e jurisprudência: uma reflexão epistemológica sobre a jurisprudentia romana a partir de Aristóteles. In: ROCHA, Leonel Severo (Org.). Anuário do programa de pós-graduação em Direito/ Unisinos. São Leopoldo, 1999).

11 CASADO, María. Nuevo derecho para la nueva genética. In: CASADO, María (Org.). Bioética, derecho y sociedad. Valladolid: Simancas, 1998.

12 JONAS, Hans. Técnica, medicinay ética, Barcelona, Paidós, 1997, p. 15.

13 JONAS, Técnica.., p. 33. 
A antiga incomunicabilidade da ciência com os valores, portanto, vem sendo visivelmente substituída pela procura de pautas éticas de comportamento, vicejando nas diversas áreas do conhecimento os comitês de ética, os códigos profissionais de ética e o ensino da ética nas universidades. No dizer de Edna Hogemann, "o interesse nas questões éticas surge a partir das situações nas quais os indivíduos não se sentem completamente seguros em relação a qual direção é a correta a seguir". ${ }^{14}$

A busca de modelos de comportamento, de respostas para como agir em relação aos conhecimentos frente a casos concretos, denota que o profissional e o cientista realmente operam sua ciência ou técnica através desta função valorativa, que, em última análise, busca o bem comum. Surge, então, a filosofia moral, que, como estudo da conduta humana, visando ordená-la a seu fim, ${ }^{15}$ possui caráter informativo das demais ciências, em especial das ciências práticas. Sabe-se, ainda, que a filosofia moral está condicionada pela ética e pela filosofia geral, completando-se, assim, a evidente ligação entre estes saberes. ${ }^{16}$

Por outro lado, as ciências sociais, e mesmo aquelas de natureza mais "técnica", estão condicionadas por epistemologias e modelos filosóficos. O método e a epistemologia de uma ciência dependem de respostas no campo da filosofia na sua feição de saber teórico.

Deste modo, como hoje parece imperar o relativismo e a fragmentação moral, sente-se a necessidade de dialogar sobre grandes temas que afetam a humanidade, buscando princípios que possam ser compartilhados por pessoas e culturas diferentes, o que é o grande desafio da nossa época. ${ }^{17}$

A função do Direito neste horizonte é essencial e inegável, bem como, para o desagrado dos racionalistas tradicionais, o resgate da metafísica, no momento em que a realidade fundante destas ciências, técnicas e princípios é a pessoa humana. Na verdade, de outra forma não poderia ser, pois, sendo o ser humano o mais perfeito dos entes e estudando a metafísica o ser enquanto

14 HOGEMANN, Edna Raquel Rodrigues Santos. Conflitos bioéticos: o caso da clonagem humana. Rio de Janeiro: Lumen Juris, 2003, p. 4-5.

$15 \mathrm{~A}$ tridimensionalidade que se observa no Direito também pode se aplicar à normatividade ética. Segundo Guy Durand, "o fato não é normativo em si mesmo. Para que ele se torne normativo deve ocorrer um julgamento de valor, um julgamento ético." (DURAND, Introdução...,. 128) A razão opera sobre o fato, reconhecendo sua natureza e normatizando-o. 16 Sobre a ligação dos diversos saberes com a Ética e a Filosofia, vide MASSINI, Carlos Ignacio. La prudencia jurídica. Buenos Aires, Abeledo-Perrot, 1982.

17 Cf. CLOTET, Bioética ..., p. 30. 
ser, fica claro que temos que recorrer a ela. A transcendência do ser humano, o que o faz pessoa, nos remete, então, não somente à ética, mas também à metafísica. ${ }^{18}$

\section{CONEXÕES ENTRE OS DIREITOS FUNDAMENTAIS E A BIOÉTICA}

É o apelo feito à metafísica ${ }^{19}$ que nos conduz ao próximo tópico deste trabalho: as conexões entre os direitos fundamentais e a Bioética. Isto porque vamos tratar diretamente com a questão da dignidade da pessoa humana e porque, neste particular, concordamos com José Luis del Barco, quando afirma que: "la pura vida biológica es demasiado pocu para dar cuenta hasta el fondo de la digna vida humana". ${ }^{20}$

Nos artigos $1^{\circ} \mathrm{a} 4^{\circ}$ da Constituição brasileira encontram-se seus princípios fundamentais, os "princípios dos princípios", ou seja, aquelas normas que traduzem as opções políticas e valorativas fundamentais da Constituição e do povo, já que captados da moralidade dominante na sociedade. ${ }^{21}$

A Constituição espanhola foi a primeira a inserir em seu texto a expressão "valores superiores". Estes "valores superiores" referidos pela Lei Maior da Espanha constituem-se, segundo Gregorio Peces-Barba, em uma "moralidade legalizada", 22 pauta axiológica esta, portanto, aceita majoritariamente.

Isto significa que, desde que dizem com a dignidade da pessoa humana, os valores superiores e especialmente a própria dignidade presentes nas Constituições são o substrato donde se extraem "as razões éticas para a obediência ao direito". ${ }^{23}$ Eles são, portanto, a base e ao mesmo tempo o fim de todo o sistema jurídico.

Certo é, contudo, que, mesmo que não sejam expressamente mencionados valores, é claro o conteúdo axiológico

19 Vide CATURELLI, Alberto. Premissas metafísicas da Bioética. In: LADUSÃNS, Stanislavs (Coord.). Questões atuais de Bioética. São Paulo: Loyola, 1990 e MONDIN, Battista. $\Lambda$ metafísica da pessoa como fundamento da Bioética. In: LADUSÃNS, Stanislavs (Coord.). Questões atuais de Bioética. São Paulo,: Loyold, 1990.

19 Para Tomás Melendo, "sin metafísica no cabe fundamentación definitiva de la bioética" (MELENDO, Tomás. Dignidad humana y bioética. Navarra, Eunsa, 1999, p. 184).

20 DEL BARCO, José Luis. Bioética de la persona: fundamentos éticos y antropológicos. Santafé de Bogotá D.C.: Universidad de La Sabana, 1998, p. 319.

21 São claramente valores morais, por exemplo, os incisos III e IV do art. $1^{\circ}$; o art. $3^{\circ} \mathrm{e}$ seus incisos I e IV; e os incisos VI, VII, VIII e IX do art. $4^{\circ}$ da Constituição de 1988.

22 DEL BARCO, José Luis. Bioética de la persona: fundamentos éticos y antropológicos. Santafé de Bogotá D.C.: Universidad de La Sabana, 1998, p. 41.

23 Ibidem, p. 44-45. 
das constituições democráticas ocidentais atuais, manifestado justamente pelo reconhecimento da dignidade da pessoa humana e dos direitos que dela derivam.

$\mathrm{O}$ art. $1^{\circ}$, III da Constituição da República Federativa do Brasil, ao consagrar a dignidade da pessoa humana como fundamento de nosso Estado democrático de direito, adere a uma filosofia determinada, comum à maioria dos Estados ocidentais: o Brasil realiza uma constitucionalização de valores a partir deste artigo, e não só em relação à dignidade da pessoa humana, mas também em relação a outros valores a ela conexos, tais como a liberdade, a igualdade, a justiça, os "valores sociais do trabalho e da livre iniciativa" (art. $1^{\circ}$, IV) e outros.

Ao constitucionalizar valores, o nosso país, assim, dota sua Constituição de conteúdo material, como bem coloca o professor Ingo Sarlet, ao referir que os direitos fundamentais, que "correspondem a explicitações em maior ou menor grau, do princípio da dignidade da pessoa humana", integram "um sistema axiológico que atua como fundamento material de todo o ordenamento jurídico". ${ }^{24}$

No Direito em geral e no ordenamento jurídico brasileiro, então, a dignidade da pessoa humana tem várias implicações, a começar por ser fim e fundamento do Direito e do Estado. Ela surge como um valor, um fim ontológico que transcende o mundo jurídico, mas dele não deixa de fazer parte. É, portanto, também, valor jurídico, pois, além de positivada, a dignidade da pessoa humana faz parte integrante do conteúdo da justiça. É, ademais, princípio constitucional e, como tal, norma jurídica.

Por seu turno, a Bioética, compreendida como aqui o fazemos, enquanto ética voltada à vida humana, lida diretamente com a noção de pessoa e da sua dignidade. Conforme del Barco, "el origen de la Bioética nos señala su destino. Nos dice qué fin persigue. Nos indica el objetivo: mantener digna la vida." ${ }^{25}$

Para exemplificar o que dizemos, trazemos à colação o Código de Ética Médica brasileiro, cujas disposições são similares às dos demais códigos, resoluções e comitês de ética da área da saúde em geral no país:

Art. $6^{\circ} \mathrm{O}$ médico deve guardar absoluto respeito pela vida humana, atuando sempre em benefício do paciente. Jamais utilizará seus conhecimentos para gerar sofrimento fisico ou moral, para o extermínio do

24 SARLET, $A$ eficácia..., p. 115-161.

25 SARLET, $A$ eficácia..., p. 318. Del Barco faz este comentário após observar como a Bioética irrompeu com vigor no cenário público, derivada de uma necessidade de tratamento ético dos problemas biomédicos. 
ser humano, ou para permitir e acobertar tentativa contra sua dignidade e integridade. ${ }^{26}$

Várias diretivas nacionais e declarações internacionais ligadas à saúde corroboram este posicionamento, como, por exemplo, os arts. $1^{\circ}$ e $2^{\circ} \mathrm{da}$ Declaração universal sobre o genoma humano e os direitos humanos:

Art. $1^{\circ} \mathrm{O}$ genoma humano constitui a base da unidade fundamental de todos os membros da família humana, assim como do reconhecimento de sua inerente dignidade e diversidade. Em sentido simbólico, é o legado da humanidade.

Art. $2^{\circ} \mathrm{A}$ ) Toda pessoa tem o direito de respeito à sua dignidade e seus direitos, independentemente de suas características genéticas. B) Essa dignidade torna imperativo que nenhuma pessoa seja reduzida a suas características genéticas e que sua singularidade e diversidade sejam respeitadas. ${ }^{27}$

Também a Declaração de Helsinki da Associação Médica Mundial, em seus "princípios básicos para toda investigação médica", dispõe:

10 [...] es deber del médico proteger la vida, la salud, la intimidad y $l a$ dignidad del ser humano. ${ }^{28}$

E a Declaração Ibero-LatinoAmericana sobre ética e genética aduz:

2. A reflexão sobre as diversas implicâncias do desenvolvimento científico e tecnológico no campo da genética humana deve ser feita levando em consideração: a) o respeito à dignidade, à identidade e à integridade humanas e aos direitos humanos reafirmados nos documentos jurídicos internacionais; b) que o genoma humano constitui parte do patrimônio comum da humanidade como uma realidade e não como uma expressão meramente simbólica; c) o respeito à cultura, às tradições e aos valores próprios dos povos. ${ }^{29}$

Com relação à doutrina, como se sabe, a idéia de dignidade da pessoa é um conceito que exsurge do cristianismo. ${ }^{30}$ Sabe-se, contudo, que na

26 CONSELHO FEDERAL DE MEDICINA. Código de Ética. Disponivel em: <http:// www.cfm.org.br/codetic.htm>. Acesso em: maio 2004 (grifo nosso).

27 UNESCO. Declaração universal sobre o genoma humano e os direitos humanos. Paris, 1997. Disponível em: http://conselho.saude.gov.br/docs/doc_ref_eticapesq/ GENOMA_DIREITOS_HUMANOS. Acesso em: maio 2004 (grifo nosso).

28 ASSOCIAÇÃO MÉDICA MUNDIAL (WMA). Declaração de Helsinki. Edimburgo, 2000. Disponível em: <http://www.bioetica.ufrgs.br>. Acesso em: maio 2004 (grifo nosso).

29 Declaração feita no México, em Manzanillo, em 1996 e revisada em Buenos Aires em 1998. In: http://www.bioetica.ufrgs.br (grifo nosso).

30 Benda é dos que sustentam tal afirmação, dizendo que: "historicamente, a garantia da dignidade humana se encontra estreitamente ligada ao cristianismo. Seu fundamento radica no fato de que o homem foi criado à imagem e semelhança de Deus." (BENDA, Ernst et al. Manual de derecho constitucional, Madri, Marcial Pons, 1996, p. 117.) tradução livre do espanhol pela autora. 
esteira de uma separação desnecessária e de uma antinomia inverídica entre fé e razão, ${ }^{31}$ os cientistas afastaram-se da metafísica e a moral secularizou-se para ingressar na "pósmodernidade". Mas, ainda que a moralidade temporal e a ciência natural de hoje desprezem os ensinamentos e argumentos de fundo religioso, a dignidade da pessoa persiste nelas profundamente arraigada, e desponta, em pleno terceiro milênio, como núcleo central deste novo campo que é a Bioética. Como bem observa Clotet:

A Bioética, independentemente dos diferentes credos religiosos e correntes filosóficas, reconhece, através dos seus maiores representantes, como Engelhardt, Veatch, Beauchamp, Gracia, Abel, Cuyás, entre outros muitos, a validade da tese kantiana ao afirmar que as coisas têm preço, enquanto que a pessoa está acima de todo e qualquer preço, pois só ela tem dignidade para não ser usada apenas como meio. ${ }^{32}$

A correlação entre os dois campos, Bioética e direitos fundamentais, mostra-se, então, de fato intensa, eis que ambos têm por base e fim a dignidade da pessoa humana. $\mathrm{O}$ alicerce ético de ambas as searas é evidente. Neste sentido, e no que tange ao Direito, corrobora María Casado, sinalando que "los derechos humanos constituyen las bases jurídicas y, a la vez, el mínimo ético irrenunciable, sobre las que deben asentarse las sociedades occidentales." ${ }^{133} \mathrm{E}$, quanto à Bioética, recorremos uma vez mais a José Luis del Barco, que crê "que es el espíritu, efectivamente, el que toca la melodía en el teclado del ADN, no al revés." ${ }^{34}$

Muitos, aliás, são os indícios desta estreita ligação entre Bioética e direitos fundamentais, a começar pelo fato de que, ao início de nosso estudo, ao apresentarmos a classificação dos direitos fundamentais em gerações ou dimensões, notamos que o avanço das ciências biomédicas é por muitos apontado como fator que justifica o nascimento de uma quarta geração de direitos, conexa intimamente a estes problemas.

Evidente também é a correlação que os princípios bioéticos encontram no mundo jurídico. Neste sentido, Lívia Haygert Pithan, ${ }^{35}$ ao tratar do surgimento e do desenvolvimento do

31 Vide Papa JOÃO PAULO II (Papa). Carta encíclica sobre as relações entre a fé e a razão, Porto Alegre: EDIPUCRS, 1998.

32 CLOTET, Bioética..., p. 199.

33 CASADO, Nuevo derecho..., p. 69.

34 Del Barco, Bioética..., p. 335.

35 PITHAN, Lívia Haygert. A dignidade humana como fundamento jurídico das "ordens de não-ressucitação" hospitalares. Porto Alegre: Edipucrs, 2004, p. 32. 
que se tem convencionado chamar de "biodireito", ensina que, para alguns juristas, "seria adequada uma incorporação dos princípios da bioética como princípios de Direito", se é que isto já não ocorre na prática.

Para que este ponto se torne mais claro, é necessário que discorramos brevemente sobre os princípios bioéticos. Deste modo, esclarece-se que existem várias abordagens ou modelos possíveis para a Bioética e que, dentre eles, destaca-se indubitavelmente o chamado "principialismo". Através desta abordagem principiológica, apresentam-se quatro princípios basilares a serem aplicados aos dilemas bioéticos: o princípio do respeito à autonomia, o princípio da não-maleficência, o princípio da beneficência e o princípio da justiça.

Para conceituar tais princípios, nos utilizaremos das lições contidas sob o verbete "bioética", do Dictionnaire d'éthique et de philosophie morale, em sua recente versão gaúcha. ${ }^{36}$

O princípio do respeito à autonomia se traduz pela capacidade do indivíduo de decidir por si mesmo (a partir do recebimento racional de informações), sem que influências externas determinem sua ação. Ele encontra paralelo, genericamente falando, nos direitos fundamentais de liberdade e autodeterminação, tais como a liberdade de ação, ligada ao princípio da legalidade, liberdade de opinião e de manifestação do pensamento, entre outros.

Os princípios da não-maleficência e da beneficência são interrelacionados e expressam, respectivamente, o dever do médico de não inflingir o mal a seu paciente e o dever de fazer o bem a outrem, que, no plano médico, requer a avaliação de riscos e benefícios para o paciente. Estes princípios, por sua vez, guardam correspondência com o direito à vida e à integridade física e moral.

Por fim, quanto ao princípio da justiça, por seu próprio nome faz-se quase desnecessário o estabelecimento de ligação com o mundo jurídico... De qualquer maneira, temse que o princípio bioético da justiça refere-se, por um lado, ao tratamento eqüitativo para todos, e por outro, à "justa distribuição de recursos destinados à saúde", ${ }^{37}$ ligando-se à justiça distributiva. No Direito, fazem companhia a este princípio os direitos de igualdade, o direito social à saúde e a própria eqüidade como princípio geral do direito.

36 PARIZEAU, Marie-Hélène. Bioética: In: CANTO-SPERBER, Monique (Org.). Dicionário de ética e filosofia moral. São Leopoldo, Unisinos, 2003, v. 1, p. 168.

37 Cf. PITHAN, A dignidade..., p. 28. 


\section{A CONSTITUIÇÃO \\ BRASILEIRA DE 1988 E A BIOÉTICA}

5.1 Indagações derivadas da subsunção de problemas bioéticos aos direitos fundamentais da Constituição pátria

$A b$ initio, cabe o esclarecimento de que o que se visa, aqui, é fornecer exemplos do enfrentamento de nossas áreas de estudo, pois o presente trabalho não pretende e nem é sede propícia a esgotar a questão. Outra premissa deste ponto é que seu objetivo é justamente levantar questionamentos, chamar a atenção aos problemas com os quais já nos deparamos ou nos depararemos em breve, dada a velocidade dos avanços da biotecnologia e das biociências. Salienta-se, ainda, que os exemplos expostos muitas vezes referem-se a vários dispositivos constitucionais e não somente àqueles a que aparecem diretamente ligados.

Realizadas estas observações, a exemplo do que fizemos em relação aos princípios bioéticos e os direitos fundamentais, passam a ser expostos alguns destes direitos constitucionalmente previstos, os principais dispositivos que os elencam, e os temas problemáticos da Bioética que os atingem. Opta-se por uma exposição em tópicos para facilitar a compreensão:

- O princípio da dignidade da pessoa humana, contido no art. $1^{\circ}$, III da Constituição, é, como dito anteriormente, a fonte dos demais direitos fundamentais e liga-se a vários problemas de natureza bioética, tais como clonagem e eugenia. Outra questão conexa à dignidade surge no momento em que a fecundação heteróloga, via bancos de esperma, impede o conhecimento de quem se é, das origens da pessoa, fazendo com que, por exemplo, uma vez adulta, a pessoa possa vir a casar-se com seu irmão biológico ou ter problemas de saúde evitáveis com o conhecimento da linhagem genética, e assim por diante. O uso do corpo humano como objeto para beneficiar terceiros, o que, em certos casos, até poderia ser aceito sob o prisma da liberdade, esbarra na dignidade, em casos como a venda de órgãos, a venda do próprio corpo como cobaia e o uso de embriões para pesquisas e tratamentos.

- O direito à vida, disposto no caput do art. $5^{\circ}$ da Constituição, é confrontado com itens como o aborto, a eutanásia e suas variantes, a cessação de tratamentos e o "descarte" de embriões não implantados no útero ou utilizados em pesquisas. Há, ainda, a relativização do valor "vida" em casos de deficiências, doenças incuráveis, velhice, etc., bem como relativiza-se a vida na produção de embriões para fins diversos do que seu desenvolvimento normal.

- Os direitos de igualdade, previstos no art. $5^{\circ}$, caput e incisos I, VIII, XLI e XLII, deparam-se com a eugenia, a discriminação genética $\mathrm{e}$ a análise do genoma para fins contratuais (contratos de seguro ou laborais, por 
exemplo). Também aqui se enquadram os problemas da seleção de embriões para serem "descartados" ou se desenvolverem (pelos mais variados motivos, desde a escolha de sexo até doação de órgãos a terceiro) e da discriminação no acesso aos recursos e técnicas de sanidade (saúde pública e privada, listas de espera para doações de órgãos, escolha entre um ou outro paciente para salvar, critérios de controle populacional via esterilização, etc.).

- O direito à integridade física e moral do art. $5^{\circ}$, III, XLIII e XLIX da Constituição relaciona-se com a esterilização, a manipulação genética, a eugenia, as experiências em seres humanos e mesmo problemas de danos morais devido à divulgação de informações genéticas.

- A proteção à intimidade, consagrada no art. $5^{\circ}, \mathrm{X}$ da Constituição, traz à tona o dever de confidencialidade do profissional da saúde e os critérios para a divulgação de dados sobre o genoma das pessoas, envolvendo inclusive o direito do paciente de optar por não saber determinadas informações.

- Os direitos de liberdade, postos no art. $5^{\circ}$, caput, e vários de seus incisos, como o II, o IV e o VI, da Constituição, enfrentam os questionamentos derivados do direito de decidir sobre tratamentos, inclusive de recusálos ou interrompê-los (surge a escusa de consciência do art. $5^{\circ}$, VIII) e também do direito de decidir sobre informações contidas no genoma. Por outro lado, não podemos deixar de considerar a liberdade de investigação científica, eis que também a ciência e a tecnologia encontram-se constitucionalmente protegidas no art. 218 .

- $\mathrm{O}$ direito à saúde, previsto no art. $6^{\circ}$ da Constituição, envolve o direito a informações genéticas para poder-se buscar tratamento; o confronto da saúde pública ante o fornecimento de tratamentos de alto custo para alguns e a ausência de condições mínimas de saúde para outros; o "utilitarismo econômico"; ${ }^{38}$ a alocação de recursos; a tomada de decisões que tenham por conseqüência a vida ou a morte de uma ou mais pessoas. Ainda no plano social, ressurgem pontos como critérios de controle populacional via esterilização, o prolongamento da vida e suas conseqüências econômicas e de seguridade social, a igualdade no acesso aos recursos e técnicas. Por fim, em sua conexão com o Estado, os direitos da família, especialmente aqueles contidos no art. $226, \S 7^{\circ}$ da Constituição, são confrontados com questões relativas ao direito de se reproduzir e à esterilização.

- O respeito à diversidade, que, além de ser uma combinação dos direitos de igualdade, liberdade e da dignidade da pessoa, está presente em diferentes passagens da Constituição, como no respeito ao pluralismo (arts. 17, 170, 206, III, 215, 216, 220, caput

38 Cf. SGRECCIA, Elio. Manual de bioética. São Paulo: Loyola, 1997, v. 2, p. 16. 
e $\S 5^{\circ}$ ), preocupa-se com tópicos como a eugenia, a clonagem, a engenharia de linhagem germinal, a discriminação relativa à opção sexual, a alteração e o controle comportamental e social pela neurofarmacologia, a manipulação genética e os critérios de controle populacional via esterilização.

Por fim, alerta-se para o fato de que muitas vezes os direitos fundamentais são colocados em oposição em função de problemas bioéticos. Assim, comumente afrontam-se direitos como liberdade (autodeterminação) e respeito à vida, intimidade e vida de um terceiro, e assim por diante.

\subsection{O papel da constituição brasileira ante os dilemas bioéticos}

Após demonstrarmos a íntima ligação da Bioética com os direitos fundamentais e de apresentarmos temas bioéticos que podem gerar situações de conflito com a declaração de direitos da Constituição brasileira, partimos em busca de resoluções a estas questões. Neste sentido, a Constituição, por si só, desponta como instrumento para a solução dos embates expostos.

O próprio elenco de direitos fundamentais da Constituição funciona como o maior limite aos exageros da biotecnologia. A Lei Maior apazigua os temores que o avanço desmesurado da técnica inflige à sociedade, que assiste à ficção tornando-se realidade e aproximando-se da vida quotidiana de todos.

Tanto quanto é bem verdade que as normas setoriais inspiram a hermenêutica constitucional, não deixa de ser verdadeiro que a Constituição também deve inspirar toda e qualquer legislação infraconstitucional relativa à Bioética, legislação esta, aliás, ainda muito incipiente no Brasil.

Além disso, a Constituição brasileira assume tarefa diferenciada em relação à Bioética, representando não só seu papel natural de norteadora das decisões judiciais, mas sendo diretamente invocada por estas, que, dada a escassez de normas sobre o assunto, muitas vezes têm de apelar à possibilidade ventilada no art. $5^{\circ}, \S 1^{\circ}$ da Lei Maior, que determina a aplicabilidade imediata das normas definidoras de direitos fundamentais.

Como máxima expressão legislativa da vontade popular, a Constituição de fato coloca a todos um "mínimo ético irrenunciável", nas palavras já citadas de María Casado, estendendo sua influência às normas deontológicas. Isto significa que, mesmo no campo deontológico próprio à área da saúde, ela não pode ser desprezada pelos operadores destas e das demais ciências e técnicas não-jurídicas, já que sua força normativa e seu véu de legitimidade e legalidade se desdobra sobre todos na sociedade.

Ao lado deste papel fundamental da Constituição, está a tarefa da hermenêutica constitucional, pois sabemos que a Constituição necessita, como as demais normas componentes do ordenamento jurídico, de concretização, mediante a ação do Poder Judiciário. A interpretação 
principiológica da Constituição ganha espaço e a ponderação de princípios se faz necessária na realidade das lides. A conexão destas realidades jurídicas com os problemas da Bioética mais uma vez é verdadeira e se apresenta como uma via de mão dupla, pois há quem defenda que "a discussão metodológica em Bioética deveria seguir o modelo da argumentação jurídica quando aborda o conflito entre princípios". ${ }^{39}$ Esta opinião é esposada por Judith Martins-Costa, quando apresenta "o Direito como construção de modelos de respostas", apontando como "ilustrativa deste modelo a Constituição Federal". ${ }^{0}$

\section{CONCLUSÃo}

Para finalizar nosso estudo, procuraremos apresentar algumas vias de ação necessárias à prevenção e à solução dos dilemas aqui apresentados. Para tanto, vamos recorrer com freqüência às idéias de Francis Fukuyama, já que nos identificamos com vários aspectos do seu pensamento.

É oportuno dizer que partimos do pressuposto da democracia, ou seja, do papel do Estado democrático de direito, que, garantindo ao máximo a liberdade possível em sociedade, tem o dever de intervir para proteger a pessoa humana que se abriga em seu seio. E, neste diapasão, vimos que a Constituição exerce importante papel.

Não cremos, entretanto, que a Constituição, sozinha, possa dar conta de orientar satisfatoriamente a jurisprudência para a solução dos casos concretos e defendemos a necessidade de leis sobre a matéria e de instituições que a regulem.

Quanto à criação de leis, basta levantar a idéia para encontrar opositores. Em primeiro lugar, porque os povos estariam fartos de leis, argumento a que, inicialmente, não podemos nos opor. É verdade que há excesso de leis, muitas delas distantes da sociedade. Todavia, como enfatiza María Casado, "en aspectos como los que atañen a la Bioética, la tendencia es justamente la contraria". A aceitação de novas normas, neste caso, dá-se por várias razões, entre elas a dificuldade em encontrar-se consenso nos diversos setores sociais, cabendo, então, ao Direito, lançar uma diretriz. Também porque são problemas ligados aos valores mais caros da sociedade e tratase de mudanças de paradigma radicais, polêmicas e nunca dantes vistas, o que leva, ainda no dizer de Casado, a uma demanda de legislação por parte da

39 Cf. MARTÍ, Francesca Puigpelat. Bioética y valores constitucionales. In: María CASADO. Bioética, derecho y sociedad. Valladolid: Simancas, 1998, p. 52, tradução livre do espanhol pela autora.

40 MARTINS-COSTA, Judith. As interfaces entre a Bioética e o Direito. In: CLOTET, Joaquim (Org.) Bioética. Porto Alegre: Edipucrs, 2001. p. 68 e 71. 
sociedade, sendo que, "a menudo los colectivos implicados directamente por los problemas son los que tratan de forzar el cambio a través del dictado de normas jurídicas". ${ }^{41}$

Obviamente, a promulgação de leis não resolve de vez a problemática, nem encerra as discussões, que, muitas vezes até se acirram. ${ }^{42}$ Isto não é motivo, porém, para defender-se o império do casuísmo, como fazem alguns estudiosos. O modelo casuístico é, inclusive, ao lado do principialismo, uma das mais difundidas abordagens propostas para a Bioética.

A espanhola Francesca Puigpelat Martí, por exemplo, é defensora do modelo casuístico, como se observa da seguinte passagem:

[...] la vía legislativa en matéria bioética no parece todavía la más prudente. [...] Al ser estas cuestiones tan personales y nuevas, la mejor forma de abordarlas es a través del análisis de cada caso. No hay experiencia suficiente sobre las nuevas situaciones para que pueda hablarse de un consenso social sobre su tratamiento." ${ }^{43}$

E continua a autora, ao comentar a legislação espanhola, defendendo:
Creo que hubiese sido más conveniente esperar a que los casos se planteasen ante los tribunales y que la opinión pública hubiese podido manifestar sus preferencias valorativas sin la presión de que ciertas conductas estén ya etiquetadas de ilegales. ${ }^{44}$

Com a devida vênia, não podemos aceitar este tipo de posicionamento. Primeiramente porque, sem desprezar a indubitável importância da análise caso a caso, não se pode deixar tudo a cargo do Poder Judiciário sob pena de desestabilizar-se o Estado democrático de direito, já que quem determina o que é o bem comum é o povo e não o Poder Judiciário. E, em segundo lugar, porque não parece a atitude mais sábia esperar para reagir depois de ter-se dado espaço para conseqüências nefastas. Fukuyama, ao comentar a legislação americana sobre experimentos em seres humanos, conta que "mais uma vez, a regulação foi impelida por escândalo e tragédia", referindo-se a conhecidos casos, onde células cancerígenas foram injetadas em pacientes debilitados, pacientes negros e pobres foram deixados sem tratamento para sífilis para que os efeitos fossem estudados, e assim por diante. ${ }^{45}$

41 CASADO, Nuevo derecho..., p. 65-66.

42 Vide as várias polêmicas em torno da chamada Lei de Biossegurança, aprovada em nosso país em 2005.

43 MARTÍ, Bioética..., p. 53.

44 Ibidem.

45 Cf. FUKUYAMA, Francis. Nosso futuro pós-humano: consequêencias da revolução da biotecnologia. Rio de Janeiro: Rocco, 2003, p. 209. 
O Poder Legislativo é representativo da sociedade e, ainda que a democracia, como regime político criado por homens imperfeitos, seja também imperfeita, "não há também nenhum conjunto alternativo obviamente melhor de instituições que possa capturar a vontade do povo de maneira justa e legítima". ${ }^{46}$ Por isso, cabe à esfera política, com a imprescindível colaboração dos cientistas, a palavra final em termos de legislação, e não o contrário, eis que "a ciência não pode estabelecer por si mesma os fins a que serve". ${ }^{47}$

Defendemos, assim, a criação de leis infraconstitucionais que regulem os problemas bioéticos, leis estas emanadas da esfera política, que deve decidir sobre fins (valores) apropriados para a biotecnologia, embasada por informações científicas dadas, estas sim, pela comunidade científica. Tudo com base no trabalho prévio de comissões interdisciplinares, buscando identificar, através do diálogo democrático e na medida do possível, o consensual e o real no que diz respeito a estes assuntos.

A menção expressa à realidade, aqui, assume posição essencial ao lado do consenso social, porque se entende que o consenso tem caráter instrumental em relação à verdade. $\mathrm{O}$ fundamento da verdade permanece sempre na coisa, na realidade, sendo o consenso um instrumento pelo qual a razão prática pode encontrar essa verdade. O próprio consenso só pode ser apreendido pela razão prática e isso só é possível na democracia. Daí defender Andrés Ollero "nenhuma democracia sem direito natural e nenhum direito natural sem democracia." ${ }^{\prime 48}$

Afora a elaboração de leis, é de se pensar, como sugere Fukuyama, na criação de instituições reguladoras para a biotecnologia e, neste particular, abrese a pauta internacional, já que, em um mundo globalizado como o atual, a homogeneidade das regulações dos diferentes Estados se faz necessária. Estas instituições ou agências seriam especialmente úteis para distinguir o que efetivamente é progresso para a vida e a dignidade humanas e o que é ameaça a elas.

É claro que também se pode duvidar da eficácia do controle da biotecnologia por instituições reguladoras, mas é de se salientar que não se trata de uma quimera, visto que regras deste tipo já são realidade, por exemplo, relativamente à experimentação em seres humanos, e isto internacionalmente.

46 Ibidem, p. 194.

47 Ibidem, p. 193.

48 OLLERO Tassara, Andrés. A crise do positivismo jurídico: paradoxos teóricos de uma rotina prática. In: COLÓQUIO INTERNACIONAL DIREITO NATURALE DIREITOS DO HOMEM NOALVORESCER DO SÉCULO XXI, Roma, 1991. 
Do mesmo modo, eventuais falhas nos sistemas regulatórios são inevitáveis, o que não ilide sua valia. Mais uma vez, buscamos auxílio na obra de Francis Fukuyama para fortalecer nossos argumentos:

[...] nenhum regime regulador é jamais completamente invulnerável, e se selecionamos um intervalo suficientemente longo, a maioria das tecnologias acaba sendo desenvolvida. Mas isso não é compreender a regulação social: nenhuma lei é jamais plenamente imposta. Todo país faz do assassinato um crime e associa penas severas ao homicídio e, ainda assim, assassinatos ocorrem. Isso nunca foi razão para se desistir da lei ou de tentativas para impor o seu cumprimento..$^{49}$

Já não agir significa legitimar as mudanças biotecnológicas e tornar a

\section{REFERÊNCIAS}

ARAÚJO, Luiz Alberto David; NUNES JÚNIOR, Vidal Serrano. Curso de Direito Constitucional.

8. ed. São Paulo: Saraiva, 2004.

ASSOCIAÇÃO MÉDICA MUNDIAL (WMA). Declaração de Helsinki. Edimburgo, 2000. Disponível em: <http://www.bioetica.ufrgs.br>. Acesso em: maio 2004.

BARRETTO, Vicente. Bioética e ordem jurídica. In: Revista da Faculdade humanidade escrava do progresso tecnológico, mesmo quando este não se dirige a fins que salvaguardem e beneficiem o humano. ${ }^{50}$

Concluímos ressaltando, por fim e uma vez mais, que é fundamental agir, no Direito e na Bioética, sempre tendo em vista a enorme dignidade da pessoa, que faz de cada um de nós um ser ao mesmo tempo único e universal em sua humanidade. Se nos for permitida uma "metáfora artística", a dignidade da pessoa humana é o ponto de fuga a partir do qual se traçam os horizontes do Direito e da Bioética. Estando este horizonte traçado, que venham os avanços da biotecnologia e completese um belo quadro de longevidade, qualidade de vida e cura para as pessoas de hoje e de amanhã.

de Direito da UERJ, Rio de Janeiro, v.1, n. 2, p. 443 - 454, 1994.

BARZOTTO, Luís Fernando. Prudência e jurisprudência: uma reflexão epistemológica sobre a iurisprudentia romana a partir de Aristóteles. In: ROCHA, Leonel Severo (Org.). Anuário do programa de pós-graduação em Direito/ Unisinos. São Leopoldo, 1999. p.163-192.

49 Ibidem, p. 197.

50 Cf. FUKUYAMA, Nosso futuro..., p. 225. 
BASTOS, Celso Ribeiro. Curso de Direito Constitucional. 22. ed. São Paulo: Saraiva, 2001.

BENDA, Ernst et al. Manual de derecho constitucional. Madrid: Marcial Pons, 1996.

BONAVIDES, Paulo. Curso de Direito Constitucional. 11. ed. São Paulo: Malheiros, 2001.

CANTO-SPERBER, Monique (Org.). Dicionário de ética efilosofia moral. São Leopoldo: Unisinos, $2003.2 \mathrm{v}$.

CASADO, María. Nuevo derecho para la nueva genética. In: CASADO, María (Org.). Bioética, derecho y sociedad. Valladolid: Simancas, 1998. p. 55 - 73.

CATURELLI, Alberto. Premissas metafísicas da Bioética. In: LADUSÃNS, Stanislavs (Coord.). Questões atuais de Bioética. São Paulo: Loyola, 1990, p. 131-146.

CLOTET, Joaquim. Bioética: uma aproximação. Porto Alegre: Edipucrs, 2003.

CONSELHO FEDERAL DE MEDICINA. Código de Ética. Disponível em: <http:// www.cfm.org.br/codetic.htm>. Acesso em: maio 2004.

DEL BARCO, José Luis. Bioética de la persona: fundamentos éticos y antropológicos. Santaféde Bogotá D.C.: Universidad de la Sabana, 1998.

DIAS, Hélio Pereira. Bioética. Implicações com as práticas médicas e as normas deontológicas e jurídicas, no Brasil. In:
ORGANIZACIÓN PANAMERICANA DE LA SALUD. Bioética: temas y perspectivas. Washington D.C.: 1990, p. 132-142.

DURAND, Guy. Introdução geral à Bioética: história, conceitos e instrumentos. Tradução Nicolás Nyimi Campanário. São Paulo: Editora do Centro Universitário São Camilo e Edições Loyola, 2003.

ENGELHARDT JÚNIOR, H. Tristram. Fundamentos da Bioética, São Paulo: Loyola, 1998.

ESPINOSA, Jaime. Questões de bioética, São Paulo: Quadrante, 1998.

FUKUYAMA, Francis. Nosso futuro pós-humano: conseqüências da revolução da biotecnologia. Rio de Janeiro: Rocco, 2003.

GOLDIM, José Roberto. Bioethics and research in Brazil. In: SALLES, Arleen L. F.; BERTOMEU, Maria Julia (Org.). Bioethics: Latin American perspectives, Amsterdan/ NY: Rodopi, 2002. p. 141-150.

HOGEMANN, Edna Raquel Rodrigues Santos. Conflitos bioéticos: o caso da clonagem humana. Rio de Janeiro: Lumen Juris, 2003.

JOÃO PAULO II (Papa). Carta encíclica sobre as relações entre a fé e a razão, Porto Alegre: EDIPUCRS, 1998.

JONAS, Hans. Técnica, medicina y ética, Barcelona: Paidós, 1997.

KIPPER, Délio José et al. (Org.). Ética em pesquisa: reflexões. Porto Alegre: Edipucrs, 2003. 
MARTÍ, Francesca Puigpelat. Bioética y valores constitucionales. In: María CASADO. Bioética, derecho y sociedad. Valladolid: Simancas, 1998, p. 35-54.

MARTINS-COSTA, Judith. As interfaces entre a Bioética e o Direito. In: CLOTET, Joaquim (Org.) Bioética. Porto Alegre: Edipucrs, 2001. p. 67-84.

MASSINI, Carlos Ignacio. La prudencia juridica. Buenos Aires: Abeledo-Perrot, 1982.

MATTE, Luiza. Considerações acerca do caráter absoluto do Princípio da Dignidade da Pessoa Humana. Revista Jurídica Consulex, Brasília: v. 7, n. 162, 15 out. 2003.

MELENDO, Tomás. Dignidad humana y bioética. Navarra: Eunsa, 1999.

MONDIN, Battista. A metafísica da pessoa como fundamento da Bioética. In: LADUSÃNS, Stanislavs (Coord.). Questões atuais de Bioética. São Paulo: Loyola, 1990. p. 147 - 174.

OLLERO Tassara, Andrés. A crise do positivismo jurídico: paradoxos teóricos de uma rotina prática. In: COLÓQUIO INTERNACIONAL DIREITO NATURAL E DIREITOS DO HOMEM NO ALVORESCER DO SÉCULO XXI, Roma: 1991. 56 p. (texto mimeografado).

PITHAN, Lívia Haygert. A dignidade humana como fundamento jurídico das "ordens de não- ressucitação" hospitalares. Porto Alegre: Edipucrs, 2004.

PROGRAMA LATINOAMERICANO DEL GENOMA HUMANO. Declaração de Manzanillo. Buenos Aires: 1998. Disponível em: $<$ http://www.bioetica.ufrgs.br>. Acesso em: maio/2004.

SARLET, Ingo Wolfgang. A eficácia dos direitos fundamentais. Porto Alegre: Livraria do Advogado, 1998.

SERRA, Angelo. Das novas fronteiras da Biologia e da Medicina-novos questionamentos para a Filosofia, para o Direito e para a Teologia. In: LADUSÃNS, Stanislavs (Coord.). Questões atuais de bioética. São Paulo: Loyola, 1990, p. 59-174.

SGRECCIA, Elio. Manual de bioética. São Paulo: Loyola, $1997.2 \mathrm{v}$.

SILVA, José Afonso da. Curso de Direito Constitucional positivo. 22. ed. São Paulo: Malheiros, 2003.

UNESCO. Declaração universal sobre o genoma humano e os direitos humanos. Paris: 1997. Disponível em: http:// conselho.saude.gov.br/docs/ doc_ref_eticapesq/GENOMA_ DIREITOS_HUMANOS. Acesso em: maio 2004.

VALLS, Ramón. Ética para la bioética. In: María CASADO. Bioética, derecho y sociedad, Valladolid: Simancas, 1998, p. $15-33$. 
